\title{
Estratégias para redução do cancelamento de cirurgias eletivas no Hospital Regional de Cotia
}

Hospital Regional de Cotia

seconcisp/OSS

Autores: SILVA, Debora Barros Silva; RAMOS, Evelin Amaral; ANDRADE, Vivian Prudêncio

\section{Introdução}

A limpeza é um processo complexo com múltiplos desafios que devem ser enfrentados para que possamos garantir a segurança do processo. A sujidade no material cirúrgico serve como barreira para a penetração do agente esterilizante, propiciando um ambiente favorável para o crescimento de microrganismos que são responsáveis pela transmissão de infecções hospitalares. A tecnologia vem aprimorando o desenvolvimento de métodos para o monitoramento do processo de limpeza, eles têm contribuído para uma prática mais segura e de qualidade, tanto para os pacientes como para equipe de saúde, otimizando o processo de trabalho nas Centrais de Material e Esterilização (CME].

Percentual de Cirurgias Ortopédicas Canceladas

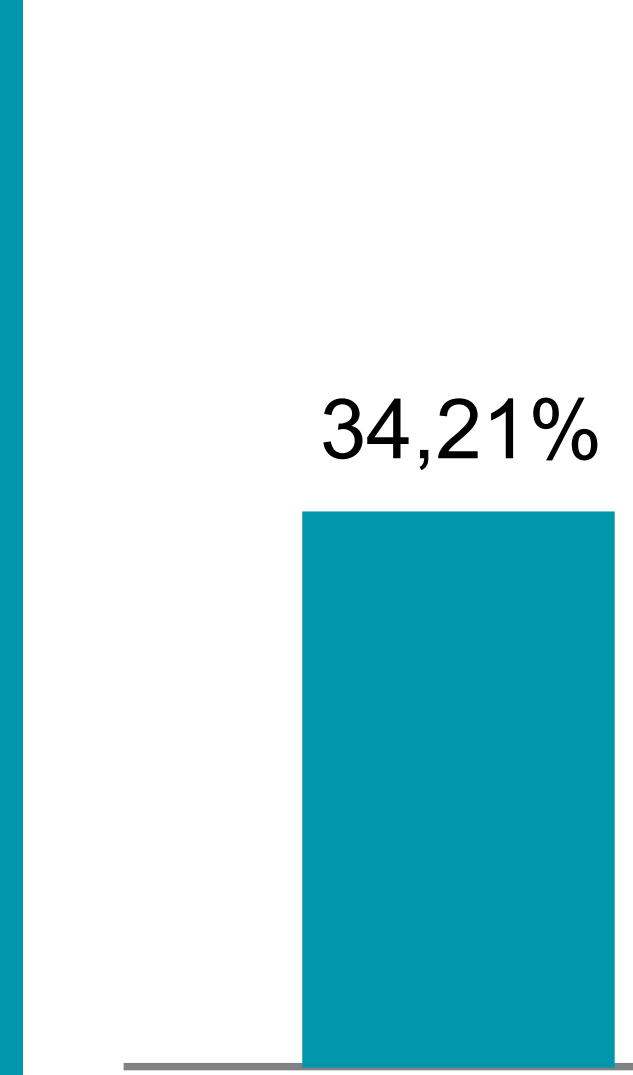

2016
2017

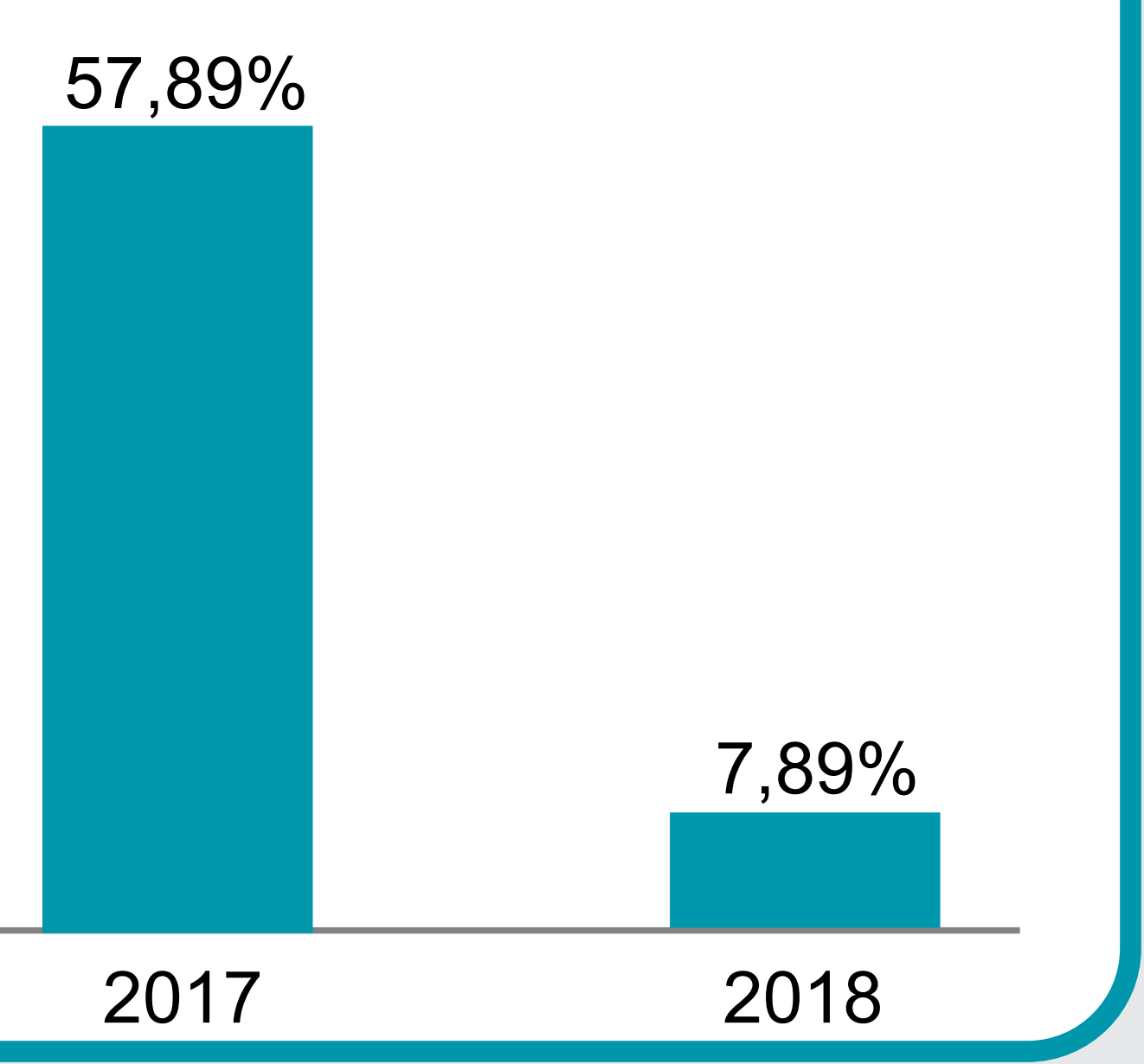

2018

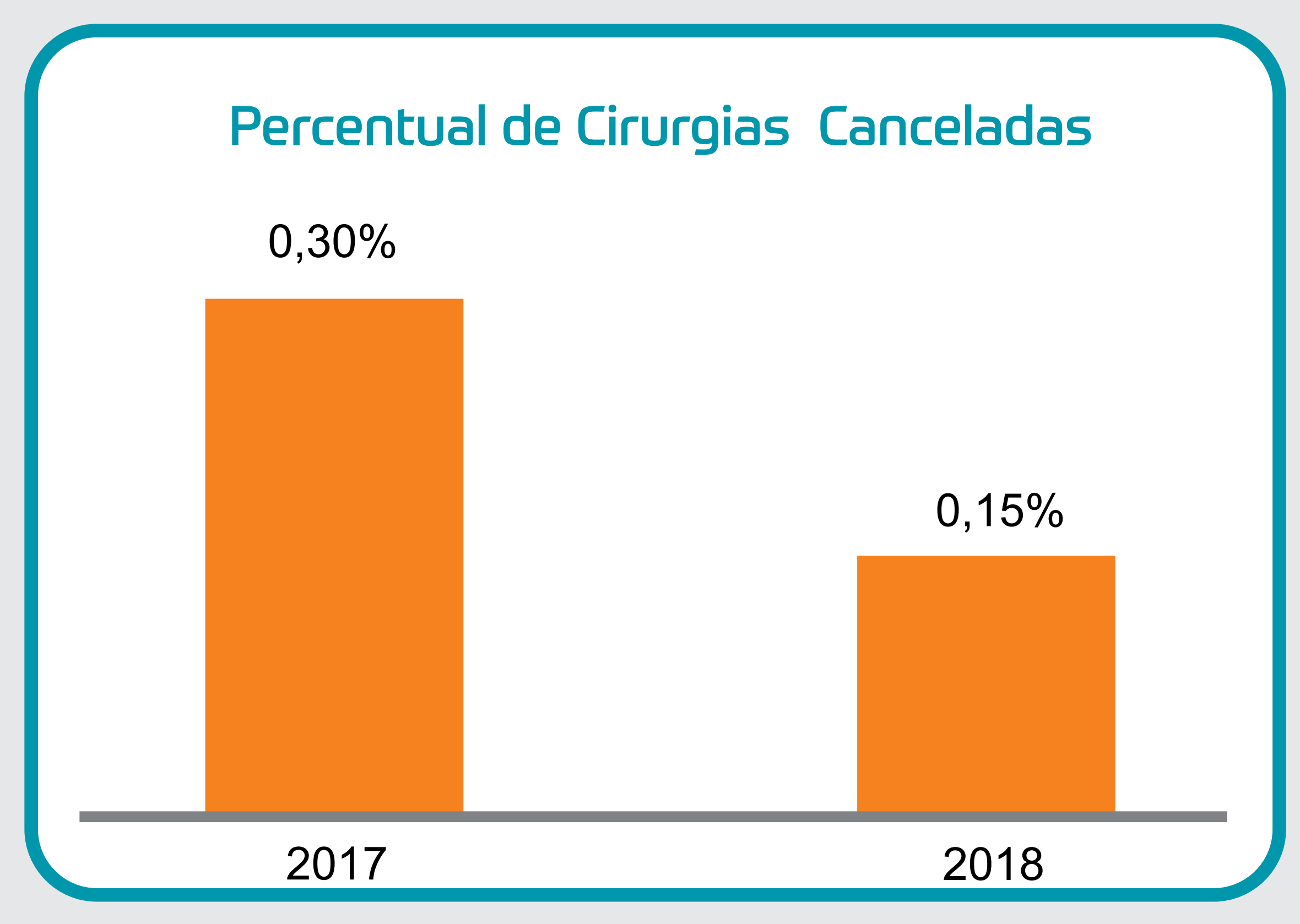

2018
Notificações de Sujidade Vs Cancelamento de Cirurgias

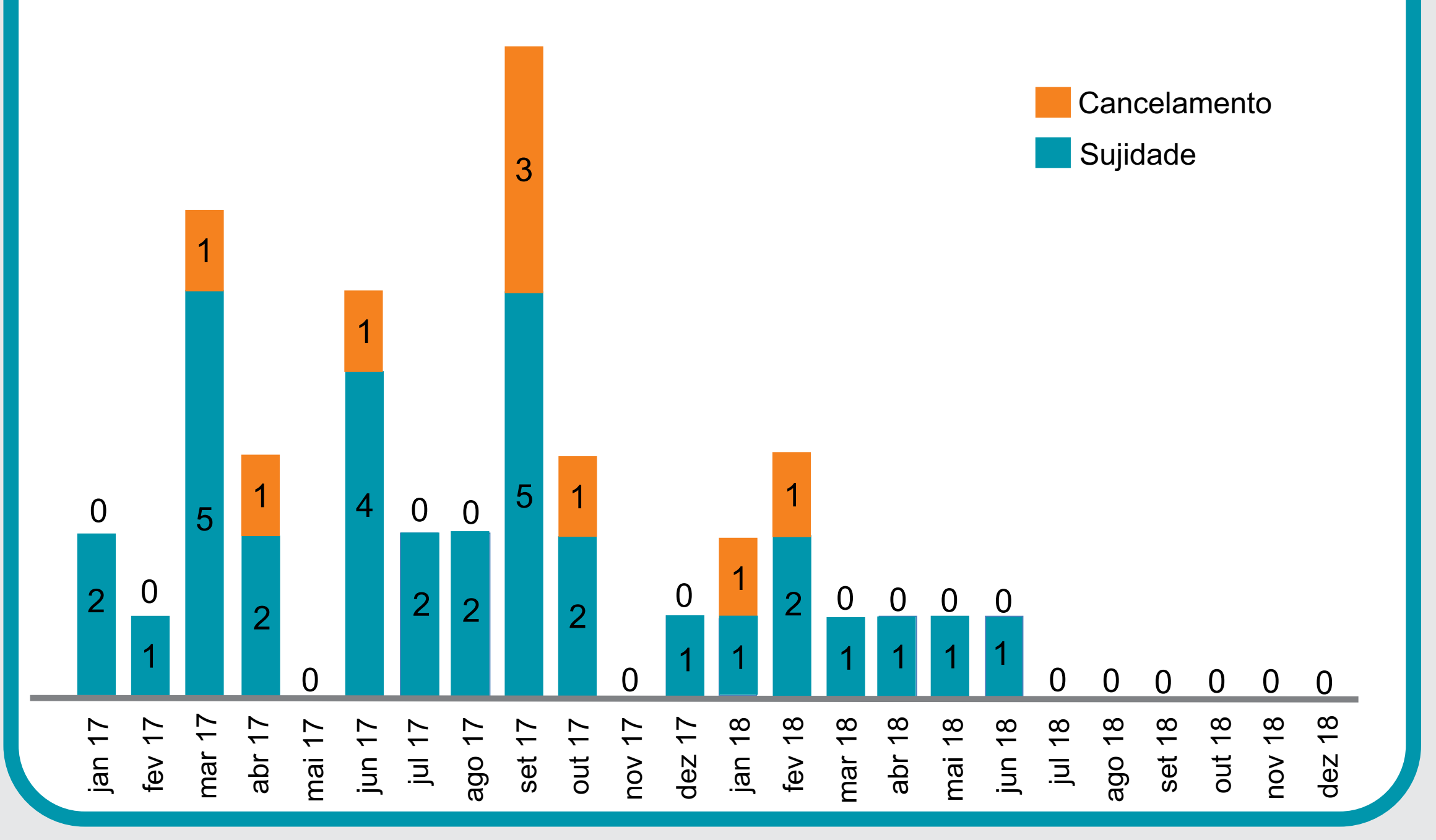

\section{Objetivo}

Reduzir o cancelamento de cirurgias eletivas ortopédicas decorrente da presença de sujidade nos materiais médicos hospitalares e aumentar a segurança do processo cirúrgico.

\section{Método}

Para identificar as sujidades nos materiais cirúrgicos, utilizou-se método de luminescência, Trifosfato de Adenosina [ATP] para a detecção de proteínas que demonstram a presença de organismos vivos, sejam elas bactérias ou biofilmes, de artigos médico-hospitalares processados na Central de Material e Esterilização. A equipe da CME utilizou a ferramenta de qualidade PDCA para análise e solução dos problemas de presença de sujidade nos artigos cirúrgicos de ortopedia. Também foram avaliadas as notificações de sujidade em materias cirúrgicos do Sistema de Notificação Interna da instituição. Após a análise, as ações realizadas no processo foram:

1. Revisão das etapas de limpeza manual, especificamente no tempo de exposição ao detergente enzimático;
2. Troca do detergente enzimático a cada uso;

3. Incorporado à limpeza automatizada, por meio da utilização da lavadora ultrassônica, para todos os instrumentais cirúrgicos ortopédicos;

4. Aprimoramento do processo de inspeção com sensibilização das equipes para utilização de lupas.

\section{Resultados}

Com a revisão do processo houve redução de 86, 3\% no número de cirurgias ortopédicas canceladas, isto é, de 22 cancelamentos no ano de 2017 para três em 2018.

\section{Conclusão}

As estratégias utilizadas foram eficazes na redução do cancelamento de cirurgias ortopédicas eletivas. Isto também contribuiu para diminuição do risco de infecção hospitalar por sujidade nos matérias, aumentando assim a segurança do processo cirúrgico minimizando riscos e melhorando a qualidade da assistência prestada ao paciente.

\section{SÃOFAULO GOVERNODOESTADO}

